\title{
Adenomyoepithelioma of Skin
}

\author{
Parul Sobti, Richa Gupta, Nita Khurana, Prabhat Shrivastava' \\ From the Department of Pathology and Department of Plastic Surgery'; \\ Maulana Azad Medical College, New Delhi, India.
}

\section{Abstract:}

Background: Adenomyoepithelioma is an uncommon neoplasm that occurs almost exclusively in the breast and rarely described at other sites. It is a biphasic tumor that arises from both myoepithelial and epithelial cells.

Case: We present a case of cutaneous adenomyoepithelioma in a 25 year old female patient presenting with a nodular lesion over the right cheek. Histopathological examination showed presence of dermal nodules composed of scattered tubules lined by cuboidal epithelial cells in a background sheet of myoepithelial cells. The epithelial and myoepithelial components were confirmed immunohistochemically using cytokeratin (CK) and smooth muscle antigen (SMA).

Conclusion: Primary cutaneous adenomyoepithelioma is an uncommon benign tumor with a good prognosis. However, failure to achieve a free resection margin may result in local recurrence or rarely, malignant transformation. Therefore, it is important to make an accurate pathologic diagnosis followed by complete excision

Key words: Adenomyoepithelioma, Skin, Smooth Muscle, Neoplasms, Keratins, Breast.

\section{Introduction}

Adenomyoepithelioma is a rare benign neoplasm that occurs almost exclusively in the breast. Adenomyoepithelioma of the breast and salivary gland is a biphasic tumor that arises from both myoepithelial and epithelial cells $[1,2]$. The neoplasm is composed of scattered tubules lined by ductlike cells in a background of myoepithelial cells [3]. It is exceedingly rare in the skin, with only few cases reported till date [4-7]. We present a case of a 25 year old female patient with a nodular lesion over the chin that revealed histopathologic and immunohistochemical features of adenomyoepithelioma.

\section{Case Report}

A 25 year old healthy, unmarried female presented to the plastic surgery OPD with an asymptomatic elliptical firm cutaneous lesion measuring $11 \times 8$ $\mathrm{mm}$ which had grown insidiously for the past five

\section{Corresponding Author: Dr. Parul Sobti}

Email: sobti.parul@gmail.com

Received: May 11,2013 | Accepted: June 6, 2013 | Published Online: July 20, 2013

This is an Open Access article distributed under the terms of the Creative Commons Attribution License (creativecommons.org/licenses/by/3.0)

Conflict of interest: None declared | Source of funding: Nil | DOl: http://dx.doi.org/10.17659/01.2013.0053 
months. There was no significant family history. The surrounding skin was normal and the lesion was not fixed to the underlying structures. There was no other cutaneous lesion. The nodule was excised with a $2 \mathrm{~mm}$ healthy margin and the defect was closed primarily in layers and the sample was sent for histopathology. The biopsy comprised of a $1.3 \times 1 \times 0.5 \mathrm{~cm}$ elliptical skin covered soft tissue. The tissue was formalin fixed and processed. Hematoxylin and eosin stained sections revealed a multinodular well circumscribed neoplasm located in the dermis with normal looking overlying epidermis. The nodules varied in size and shape and each nodule was surrounded by a compressed fibrous pseudocapsule. The nodules comprised of cells present in sheets with scattered tubular structures. Most of the cells present in sheets displayed myoepithelial morphology with polygonal to plasmacytoid shape and clear to granular cytoplasm. These cells were predominantly present as solid sheets, but also formed cords at places. The tubular and ductal structures were especially evident at the margin of nodules and some contained

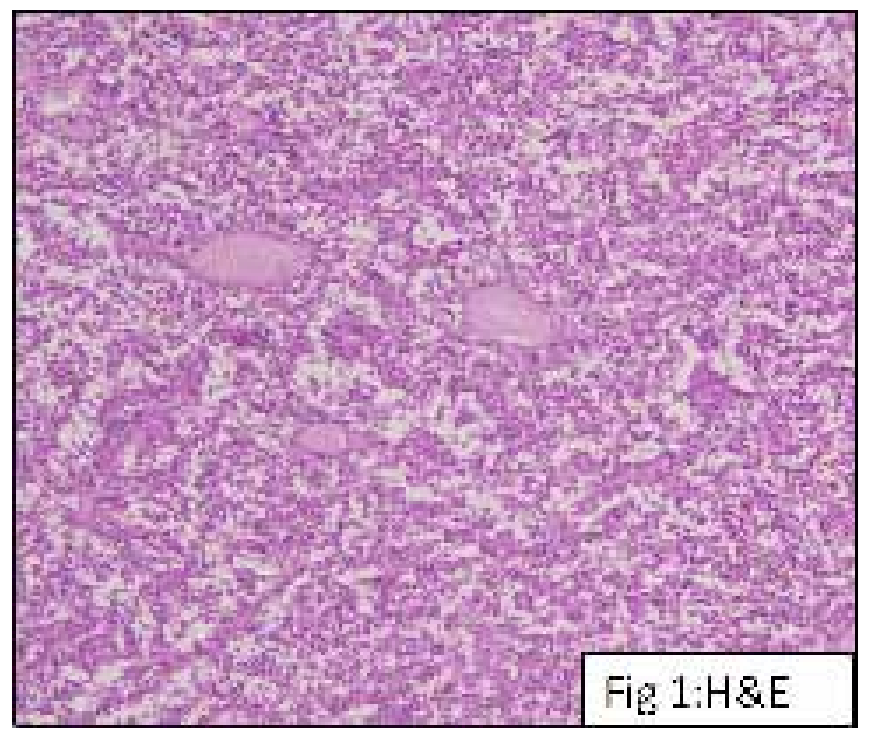

Fig. 1: Biopsy shows cells present in sheets with scattered tubular structures. Most cells show myoepithelial morphology with polygonal to plasmacytoid shape and clear to granular cytoplasm. Some tubules have apocrine-type secretion in the lumen [H\&E, 400X]. apocrine-type secretion in the lumen. Mitosis was scant involving less than one-tenth high power fields. The resection margins were free of tumor [Fig.1]. On immunohistochemistry, the cells lining the tubules were positive for cytokeratin [Fig.2] confirming their epithelial nature while the cells present in sheets were positive for smooth muscle actin (myoepithelial origin) [Fig.3]. Stains for epithelial membrane antigen (EMA) and $\mathrm{HMB}-45$ were negative.

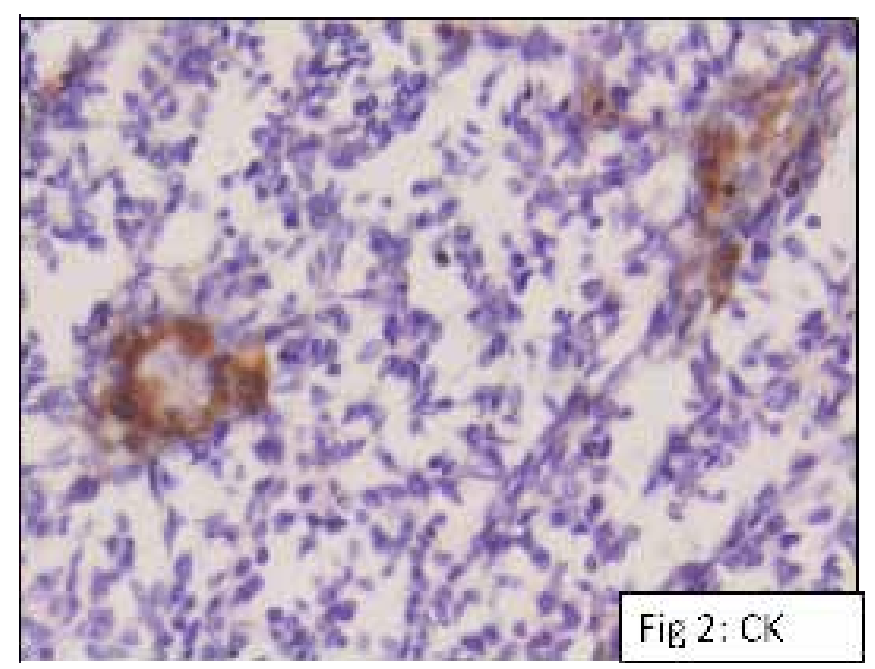

Fig.2: The myoepithelial cells were positive for smooth muscle actin [400X].

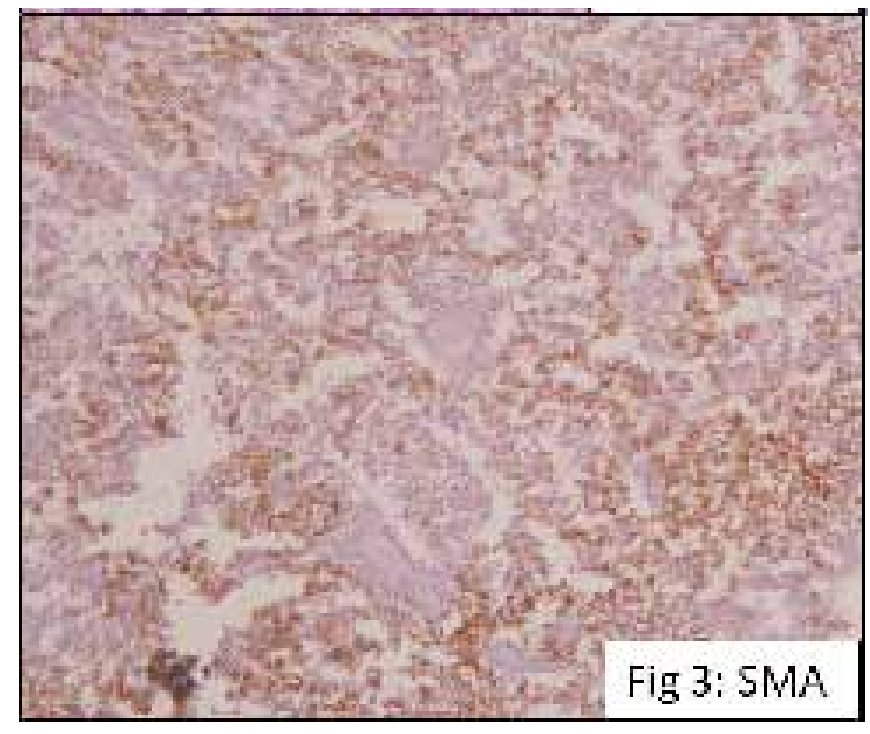

Fig.3: The glandular structures were positive for cytokeratin [400X]. 
Post operative course was smooth and uneventful. The patient has remained recurrence free and asymptomatic till 11 months follow up period so far. No additional treatment was required.

\section{Discussion}

We describe a cutaneous neoplasm composed of myoepithelial cells and a focal epithelial and glandular component. Based on findings by conventional microscopy and immunohistochemistry, this lesion showed myoepithelial differentiation and focal epithelial lined tubules that are consistent with the diagnosis of primary adenomyoepithelioma of the skin.

Adenomyoepithelioma is an uncommon tumor mainly described in the breast characterized by the presence of both epithelial and myoepithelial cells. Its detailed description was published in 1970 by Hamperl [7]. Primary cutaneous adenomyoepithelioma is even rarer. It shares some histopathologic features with common cutaneous lesions such as spiradenomas and benign mixed tumors (chondroid syringomas). It is a part of the spectrum of epithelial-myoepithelial tumors that includes benign mixed tumor, myoepithelioma and myoepithelial carcinoma. Like its breast counterpart, primary cutaneous adenomyoepithelioma should probably be regarded as a neoplasm of borderline malignant potential [8].

While myoepitheliomas are benign neoplasms consisting exclusively of myoepithelial cells embedded in a myxoid stroma, adenomyoepithelioma shows in addition to myoepithelial cells a second component displaying various degrees of epithelial-ductal differentiation [9,10]. Adenomyoepitheliomas of the breast have been further classified as tubular, lobulated or spindled subtype [3]. The most common pattern is the tubular type with features characterized by proliferation of glandular cells and surrounding myoepithelial cells of abundant clear cytoplasm. Malignant changes from epithelial, myoepithelial or both components have been described [ 11 1].

Cutaneous myoepitheliomas occur usually in children and young adults and are located on the extremities, while mixed apocrine tumors affect older individuals and are usually found on the face $[9,12]$. The few cases of cutaneous adenomyoepitheliomas that have been described to date were reported in older patients and were located on the extremities and on the trunk $[8,9]$.

In the skin, the predominance of myoepithelial cells in relation to ductal epithelial structures lacking features of follicular and/or sebaceous differentiation separates this neoplasm from mixed apocrine tumor. Therefore, myoepithelioma, adenomyoepithelioma and mixed apocrine tumor lie in the spectrum of neoplasms with pure myoepithelial differentiation at one end and apocrine-sebaceous-follicular differentiation at the other [13]. Immunostaining for smooth muscle actin and calponin can support the myoepithelial differentiation and no reactivity is noted in epithelial cells. S-100 protein have been used as a marker of myoepithelial cells in the breast, however, its immunoreactivity is not consistent and may be expressed in both myoepithelial cells and epithelial cells. Therefore, it is not a reliable marker to myoepithelial cells in adenomyoepitheliomas [14]. Presence of nuclear pleomorphism and mitosis would suggest the potential for locally aggressive behavior and/or metastasis, as has been rarely described in adenomyoepitheliomas of the breast $[15,16]$.

The exact etiology of breast adenomyoepithelioma is still obscure. All cases have been sporadic and no familial aggregation has been observed. Choi et al [17] proposed that adenomyoepithelioma was derived from a myoepithelial long standing underlying breast disease, such as adenosis and fibroadenoma. In addition, proliferative myoepithelial cells with clear cytoplasm may mimic malignancy in an intraoperative frozen section causing considerable diagnostic problem. The literature search did not 
reveal any specific etiological factors for cutaneous adenomyoepithelioma.

The present case was seen in a young female with no significant family history and had been growing insidiously for 5 months. She had no other cutaneous or breast nodules. The lesion was a well circumscribed multinodular dermal lesion, surrounded by a pseudocapsule. The lesion was comprised of cells present as sheets, cords and tubules. The cells were plasmacytoid in shape with scant mitosis. There was minimal cellular pleomorphism, no necrosis and no invasion. Immunohistochemistry revealed cytokeratin positivity in luminal and smooth muscle actin positivity in the basal cells. Post operative course was uneventful and the patient is free of recurrence for the follow up period of 11 months. Good prognosis of patients with adenomyoepithelioma has been reported. Failure to achieve a free resection margin may result in local recurrence or rarely, malignant transformation. The resection margins in the present case were free.

It is important to make an accurate pathologic diagnosis and arrange proper management for this kind of rare tumor. Presence of mitotic activity, necrosis, and cellular pleomorphism, and invasion at the periphery of the tumor indicate potential for locally aggressive behavior and/or metastasis which has been described in adenomyoepitheliomas of breast $[18,19]$. The present case did not exhibit any of these high risk features. Thus it is recommended that cutaneous adenomyoepitheliomas should be completely excised as in the present case.

\section{References}

1. Crissman JD, Wirman JA, Harris A. Malignant myoepithelioma of the parotid gland. Cancer. 1977;40:3042-3049.

2. Rosen PP. Adenomyoepithelioma of the breast. Hum Pathol. 1987; 18:1 232-1 237.

3. Tavassoli FA. Myoepithelial lesions of the breast. Myoepitheliosis, adenomyoepithelioma, and myoepithelial carcinoma. Am J Surg Pathol. $1991 ; 15: 554-568$.

4. Hartz PH. Adenomyoepithelioma of sweat gland; report of a case. Am J Clin Pathol. 1946; 16:385-390.

5. Gubareva AV. Adenomyoepithelioma of the skin. Arkh Patol. 1965;27:32.

6. Wallis NT, Banerjee SS, Eyden BP, Armstrong GR. Adenomyoepithelioma of the skin: a case report with immunohistochemical and ultrastructural observations. Histopathology. 1997;31:374377.

7. Hamperl H. The myothelia (myoepithelial cells). Normal state; regressive changes; hyperplasia; tumors. Curr Top Pathol. 1970;53:161-220.

8. Clarke LE, Seykora JT. Primary cutaneous adenomyoepithelioma. J Cutan Pathol. 2007; 34:654-657.

9. Wallis NT, Banerjee SS, Eyden BP, Armstrong GR. Adenomyoepithelioma of the skin: a case report with immunohistochemical and ultrastructural observations. Histopathology. 1997;31:374377.

10. Hornick JL, Fletcher CD. Cutaneous myoepithelioma: a clinicopathologic and immunohistochemical study of 14 cases. Hum Pathol. 2004;35: 14-24.

11. Ahmed AA, Heller DS. Malignant adenomyoepithelioma of the breast with malignant proliferation of epithelial and myoepithelial elements: A case report and review of the literature. Arch Pathol Lab Med. 2000; 1 24:632-636.

12. Kazakov DV, Belousova IE, Bisceglia $M$, et al. Apocrine mixed tumor of the skin ("mixed tumor of the folliculosebaceous-apocrine complex"). Spectrum of differentiations and metaplastic changes in the epithelial, myoepithelial, and stromal components based on a histopathologic study of 244 cases. J Am Acad Dermatol. 2007;57:467-483.

13. Gillett CE, Bobrow LG, Millis RR. S100 protein in human mammary tissue immunoreactivity in 
breast carcinoma, including Paget's disease of the nipple, and value as a marker of myoepithelial cells. J Pathol. 1990;160:19-24.

14. Riedl E, Gottlieb GJ. Primary adenomyoepithelioma of the skin - a variant of apocrine mixed tumor? Dermatol Pract Conc. $2012 ; 2: 8$.

15. Seifert G. Are adenomyoepithelioma of the breast and epithelial myoepithelial carcinoma of the salivary glands identical tumours? Virchows Arch. 1998;433:285-288.

16. Huang CY, Sheen-Chen SM, Eng HL, Ko SF. Adenomyoepithelioma of the breast. Tumori.
2007;93:493-495.

17. Choi JS, Bae JY, Jung WH. Adenomyoepithelioma of the breast-its diagnostic Problems and histogenesis. Yonsei Med J. 1996;37:284-289.

18. Rasbridge SA, Millis RR. Adenomyoepithelioma of the breast with malignant features. Virchows Arch. 1998;432:123-130.

19. Chen PC, Chen $C_{k}$, Nicastri AD, Wait RB. Myoepithelial carcinoma of the breast with distant metastasis and accompanied by adenomyoepithelioma. Histopathology. 1994; 24:543-548. 